\title{
RECOVERY FROM NUCLEAR DISASTER IN FUKUSHIMA: COLLABORATION MODEL
}

\author{
Noboru Takamura $^{1, *}$, Makiko Orita ${ }^{1}$, Yasuyuki Taira ${ }^{1}$, Yoshiko Fukushima ${ }^{2}$ and Shunichi Yamashita ${ }^{3}$ \\ ${ }^{1}$ Department of Global Health, Medicine and Welfare, Atomic Bomb Disease Institute, Nagasaki \\ University, 1-12-4 Sakamoto, Nagasaki 8528523, Japan \\ ${ }^{2}$ Department of Nursing, Nagasaki University Graduate School of Biomedical Sciences, 1-12-4 Sakamoto, \\ Nagasaki 8528523, Japan \\ ${ }^{3}$ Department of Radiation Medical Sciences, Atomic Bomb Disease Institute, Nagasaki University, 1-12-4 \\ Sakamoto, Nagasaki 8528523, Japan \\ *Corresponding author: takamura@nagasaki-u.ac.jp
}

\begin{abstract}
Since 2011, Nagasaki University has been assisting the reconstruction efforts of Kawauchi Village in the Fukushima Prefecture, which was the first village to declare it safe for residents to return to their homes. In April 2013, Nagasaki University and the Kawauchi government office concluded an agreement concerning comprehensive cooperation toward reconstruction of the village. The present study evaluates the internal and external exposure doses of residents and conducted a risk communication based on each resident's radiation dose. Furthermore, researchers began a comprehensive support of Tomioka residents who have returned to their hometown in 2017. Based on the experiences in Kawauchi village, it is clear that the cooperation of residents, local authorities and specialists is essential for the recovery of areas affected by the nuclear disaster. Accumulated experiences and practices should be carefully evaluated and recorded to prepare for future unexpected nuclear disasters.
\end{abstract}

\section{ESTABLISHMENT OF A SATELLITE OFFICE OF NAGASAKI UNIVERSITY IN KAWAUCHI VILLAGE}

Immediately after the accident at the Fukushima Daiichi Nuclear Power Station (FDNPS) in March 2011, an evacuation order was issued, to minimize residents' external radiation exposure. On 11 March 2001, the Governor of the Fukushima Prefecture issued instructions for the evacuation of all settlements within $2 \mathrm{~km}$ of the FDNPS ${ }^{(1)}$. That same day, the Director-General of the Nuclear Emergency Response Headquarters (Prime Minister) ordered the evacuation of all individuals within $3 \mathrm{~km}$ of the FDNPS, and then the evacuation radius was expanded to $20 \mathrm{~km}$ later that day. On 15 March 2011, instructions were issued ordering all people living between 20 and $30 \mathrm{~km}$ from the FDNPS to shelter in place ${ }^{(1-3)}$.

Kawauchi village, in the Fukushima Prefecture, is located within $30 \mathrm{~km}$ of the FDNPS (Figure 1). After the sheltering instructions were issued, almost all residents of the village evacuated, with $75 \%$ relocating to the city of Koriyama, where the Kawauchi government office had relocated its offices ${ }^{(4)}$. After the declaration of the termination of the accident by the Prime Minister in December 2011, the mayor of Kawauchi village decided to return to the town.

Nagasaki University has been assisting in Kawauchi village's recovery efforts through the evaluation of internal and external exposure doses and risk communication with residents based on their individual doses. In December 2011, we estimated the external radiation exposure doses of residents of Kawauchi through the measurement of radiocesium concentrations in the soil samples collected from the residential areas of the village. The estimated external effective doses from soil samples were $0.0011-0.38 \mu \mathrm{Sv} / \mathrm{h}(0.010-3.3 \mathrm{mSv} / \mathrm{y})$ within the $20-30 \mathrm{~km}$ radius from FDNPS. We could show that the risk of external radiation exposure of residents was sufficiently low in Kawauchi Village ${ }^{(5)}$.

In March 2012, the village office of Kawauchi relocated its function in the village, and the residents started returning back. In May 2012, a public health nurse from Nagasaki University stayed for an extended period to conduct individual consulting on radiation exposure and health ${ }^{(6)}$. And in April 2013, a comprehensive agreement was concluded between Nagasaki University and the Kawauchi village office, and a satellite office of Nagasaki University was established in the village. From this satellite office, researchers have been working with residents and village office ${ }^{(6)}$. This article reports on recent activities in Kawauchi village and the town of Tomioka, whose residents returned home in April 2017.

\section{FOLLOW-UP OF RADIOCESIUM CONCENTRATIONS IN WILD MUSHROOMS AND EDIBLE WILD PLANTS}

Based on the experiences of the Chernobyl accident, it is well known that radiocesium concentrates in wild mushrooms ${ }^{(6)}$. However, Kawauchi village was known for wild mushrooms even before the accident, 


\section{N. TAKAMURA ET AL.}

and its residents have enjoyed collecting and eating various mushroom varieties. After the accident, many residents had concerns about recovering their 'mushroom culture'. The researchers discussed this with residents of the village and began a collaboration, known as the 'mushroom map' project, in 2013, aiming to clarify the situation of radiocesium contamination of mushrooms in the village. Residents were asked to bring in the mushrooms they collected in the village and the concentrations of radiocesium were measured ${ }^{(7,8)}$. Researchers also calculated the committed effective doses and reported the results to residents. Recently, data on the results of the mushroom map project between 2014 and 2015 have been reported. They show that,

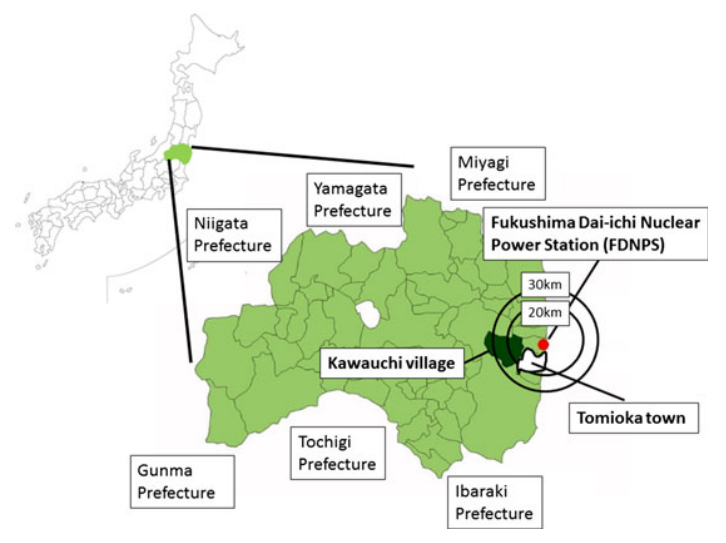

Figure 1. Kawauchi village and Tomioka town. in more than $90 \%$ of mushrooms, concentrations of radiocesium were still detectable (Figure 2$)^{(8)}$. We noticed that most species showed relatively higher concentrations of radiocesium and that several species showed relatively lower concentrations. This suggests that the concentration of radiocesium might depend on the species of mushroom. Usually, habitat varies depending on species. Yoshida and Muramatsu $^{(9)}$ found that the habitat of the mycelium seemed to be one of the most important factors controlling radiocesium concentration in mushrooms. Since habitat is closely associated with each particular species, it is suspected that species type is also associated with radiocesium concentrations in mushrooms.

In addition to wild mushrooms, it has been clarified that radiocesium is also frequently observed in edible wild plants ${ }^{(10,11)}$. With this in mind, the researchers also evaluated the concentrations of edible wild plants collected in Kawauchi village by residents and found that $10 \%$ of them showed concentrations of radiocesium at a level of $100 \mathrm{~Bq} / \mathrm{kg}$.

Regular meetings are held with residents to report these results and to discuss the future direction of the projects aiming for the recovery of the village. We emphasized that although radiocesium was detected in most mushrooms collected in the village, committed effective doses are limited even if residents consumed them several times. Such communications, based on collaboration between residents and specialists, have become one of the leading models for recovery from the nuclear disaster, and we noticed that 'face to face discussion' based on own 'dose' of each resident is very important during the recovery phase after the nuclear disaster.
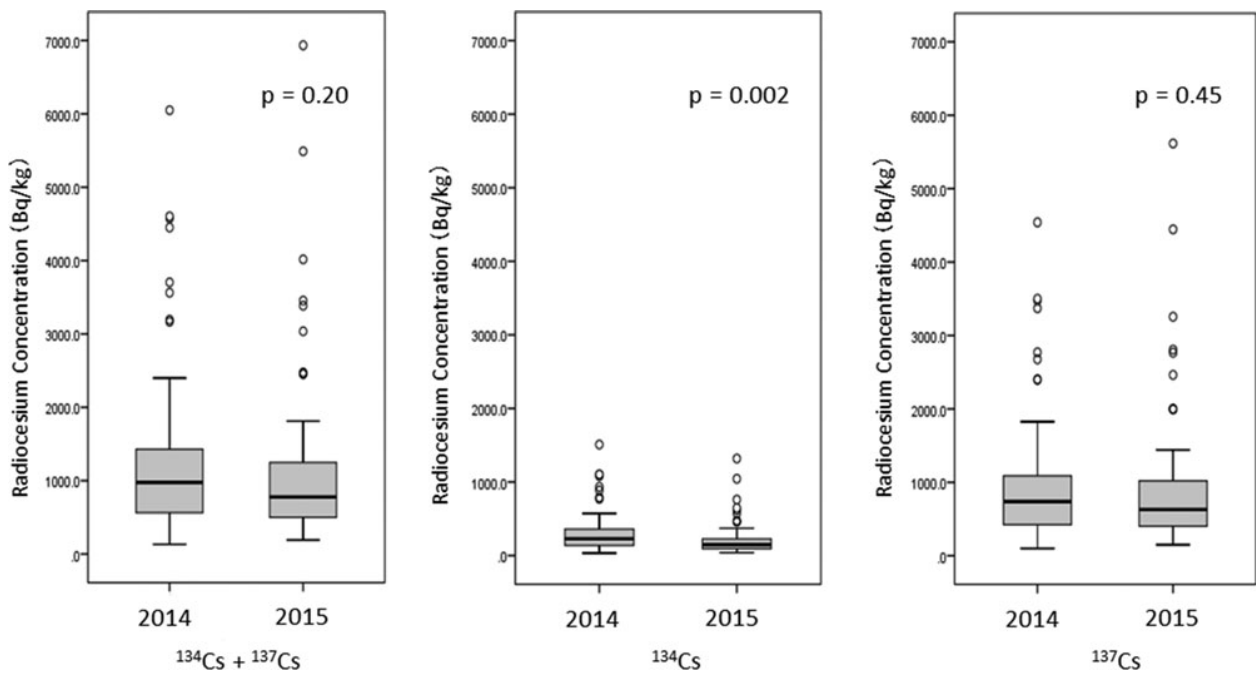

Figure 2. Comparison of concentration of radiocesium of Sarcodon aspratus collected in 2014 and $2015^{(8)}$. 


\section{RECOVERY FROM NUCLEAR DISASTER IN FUKUSHIMA}

\section{ASSESSMENT OF INDIVIDUAL DOSES FOR THE LIFTING OF EVACUATION ZONES IN KAWAUCHI VILLAGE}

Although the residents of Kawauchi village began returning to their homes in March 2012, residents who had been living within $20 \mathrm{~km}$ of the village could not return until the evacuation order was lifted. In collaboration with the village office, the external doses of residents who were living in the evacuation zone and temporarily returned to their homes were measured using personal dosemeters. This allowed for the prediction of residents' exposure doses after the evacuation order was lifted and showed that these additional external exposure doses were relatively limited in the area within $20 \mathrm{~km}$ of the village ${ }^{(12)}$. Based on these results, residents, the Kawauchi village office, and the Japanese government discussed and decided to lift the evacuation order. In April 2013, 1 year after people began returning to the village, rate of returned residents was almost $50 \%$ of the pre-accident total population. By May 2017, the rate of returned residents had increased to $80 \%$. Kawauchi village and its residents continue to receive support for further recovery and development.

\section{ESTABLISHMENT OF SATELLITE OFFICE OF NAGASAKI UNIVERSITY IN TOMIOKA TOWN}

The town of Tomioka is located within $20 \mathrm{~km}$ of the FDNPS (Figure 1). After the accident, its residents town evacuated to Kawauchi village, and the town office finally relocated to Koriyama city. Before the accident, the total population was almost 160000 , and the town of Tomioka played a central role in the Futaba region, including Kawauchi village, where the FDNPS is located.

In 2017, the evacuation order for Tomioka was partially lifted. Although decontamination efforts were complete, it had been clarified that most residents did not plan to return to Tomioka, since many had established their new lives in the places to which they evacuated. However, the recovery of Tomioka was still deemed essential for the recovery of the Futaba region.

To support this recovery, a comprehensive agreement was concluded between Nagasaki University and the town itself in September 2016. Since April 2017, when the Tomioka town office reopened in the town, the researchers established a satellite office there and began to support the town's recovery. Although the number of residents who have returned remains limited, it is believed that the provision of continuous support for Tomioka, based on the similar experiences in Kawauchi village, are important for the recovery of the Futaba area from the nuclear disaster.

\section{CONCLUSION}

As the Chernobyl accident made clear, the direct involvement of local stakeholders in the day-to-day management of a radiological situation is feasible, and there is evidence of the potential for implementing many protective actions in residents' day-to-day lives, in addition to the collective actions taken by the authorities ${ }^{(13-15)}$. However, after the Chernobyl accident, no local authorities returned to their homes after the evacuation. This means that Kawauchi village is the first local authority to have returned to its hometown after an evacuation due to a nuclear disaster. As this work has made clear, the cooperation of residents, local authorities, and specialists is essential for the recovery of areas affected by nuclear disasters, and its potential for success is shown through our experiences in Kawauchi village. Accumulated experiences and practices should be carefully evaluated and recorded to prepare for future unexpected nuclear disasters.

\section{REFERENCES}

1. Nuclear Emergency Response Headquarters of Japanese Government. Report of Japanese Government to the IAEA Ministerial Conference on Nuclear Safety. The Accident at TEPCO's Fukushima Nuclear Power Stations. Available on http://japan.kantei.go.jp/kan/ topics/201106/iaea_houkokusho_e.html (accessed on 25 September 2017).

2. Nuclear Emergency Response Headquarters of Japanese Government. Additional Report of the Japanese Government to the IAEA-The Accident at TEPCO's Fukushima Nuclear Power Stations (Second Report). Available on https://www.iaea.org/sites/ default/files/japanreport120911.pdf\#search $=\% 272$.

+ Nuclear+Emergency+Response+Headquarters+of +Japanese+Government.+Additional+report+of+the + Japanese+Government+to+the+IAEA++The + accident+at+TEPCO $\% 27 \mathrm{~s}+$ Fukushima+Nuclear + Power+Stations+ $\% 28$ Second + Report $\% 29 \% 27$ (accessed on 24 September 2017).

3. United Nations Scientific Committee on the Effects of Atomic Radiation (UNSCEAR). UNSCEAR 2013 Report Volume I. Report to the general assembly scientific annex A: levels and effects of radiation exposure due to the nuclear accident after the 2011 great eastJapan earthquake and tsunami. Available on http:// www.unscear.org/docs/reports/2013/13-85418_Report_ 2013_Annex_A.pdf (accessed on 25 September 2017).

4. Orita, M., Hayashida, N., Urata, H., Shinkawa, T., Endo, Y. and Takamura, N. Determinants of the return to hometowns after the accident at Fukushima Dai-ichi nuclear power plant: a case study for the village of Kawauchi. Radiat. Prot. Dosim. 156, 383-385 (2013).

5. Taira, Y., Hayashida, N., Yamaguchi, H., Yamashita, S., Endo, Y. and Takamura, N. Evaluation of environmental contamination and estimated radiation doses for the return to residents' homes in Kawauchi Village, Fukushima prefecture. PLoS One 7, e45816 (2012). 


\section{N. TAKAMURA ET AL.}

6. Takamura, N., Taira, Y., Yoshida, K., NakashimaHashiguchi, K., Orita, M. and Yamashita, S. Communicating radiation risk to the population of Fukushima. Radiat. Prot. Dosim. 171, 23-26 (2016).

7. Nakashima, K., Orita, M., Fukuda, N., Taira, Y., Hayashida, N., Matsuda, N. and Takamura, N. Radiocesium concentrations in wild mushrooms collected in Kawauchi Village after the accident at the Fukushima Daiichi Nuclear Power Plant. PeerJ 3, el427 (2015).

8. Orita, M., Nakashima, K., Taira, Y., Fukuda, T., Fukushima, Y., Kudo, T., Endo, Y., Yamashita, S. and Takamura, N. Radiocesium concentrations in wild mushrooms after the accident at the Fukushima Daiichi Nuclear Power Station: follow-up study in Kawauchi village. Sci. Rep. 7, 6744 (2017).

9. Yoshida, S. and Muramatsu, Y. Accumulation of radiocesium in basidiomycetes collected from Japanese forests. Sci. Total Environ. 157, 197-205 (1994).

10. Taira, Y., Hayashida, N., Orita, M., Yamaguchi, H., Ide, J., Endo, Y., Yamashita, S. and Takamura, N. Evaluation of environmental contamination and estimated exposure doses after residents return home in Kawauchi Village, Fukushima Prefecture. Environ. Sci. Technol. 48, 4556-4563 (2014).
11. Orita, M., Nakashima, K., Hayashida, N., Endo, Y., Yamashita, S. and Takamura, N. Concentrations of radiocesium in local foods collected in Kawauchi village after the accident at the Fukushima Dai-ichi Nuclear Power Station. Sci. Rep. 6, 28470 (2016).

12. Orita, M., Hayashida, N., Taira, Y., Fukushima, Y., Ide, J., Endo, Y., Kudo, T., Yamashita, S. and Takamura, N. Measurement of individual doses of radiation by personal dosimeter is important for the return of residents from evacuation order areas after nuclear disaster. PLoS One 10, e0121990 (2015).

13. Dubreuil, G. H. et al. Chernobyl post-accident management: the ETHOS project. Health Phys. 77, 361-372 (1999).

14. Lochard, J. Rehabilitation of living conditions in territories contaminated by the Chernobyl accident: the ETHOS project. Health Phys. 93, 522-526 (2007).

15. Lochard, J. et al. International Commission on Radiological Protection. ICRP Publication 111-application of the Commission's recommendations to the protection of people living in long-term contaminated areas after a nuclear accident or a radiation emergency. Ann. ICRP 39, 7-62 (2009). 